\title{
In Good Condition The Discourse of Patina as seen in Interactions between Experts and Laymen in the Antiques Trade
}

\author{
By Karin Wagner
}

\begin{abstract}
This article examines how notions of patina are conveyed by experts in the antiques trade. How do antiques experts convey perceptions of patina to their clients and audience? How do they explain, persuade, and put forward their standards of condition? Three examples are analysed, a conversation about a sundial from the Swedish Antiques Roadshow, a conversation about a toy car from the British Antiques Roadshow and a vintage watches collecting guide from Christie's auction house. Different persuasive strategies and styles used by the experts to convey their norms are identified. A change towards higher appreciation of patina can be discerned. Furthermore, the article analyses patina in regard to the relationship between surface and core of an object and in regard to use and usefulness. It is suggested that objects with patina are popular because we as humans feel an affinity with them. If things have a life trajectory, it will also involve ageing, and by surrounding ourselves with old, imperfect things we can come to terms with our own ageing process.
\end{abstract}

Keywords: patina, antiques, discourse analysis, consumption, antiques trade, Antiques Roadshow

Wagner, Karin: "In Good Condition: The Discourse of Patina as seen in Interactions between Experts and Laymen in the Antiqes Trade", Culture Unbound, Volume 11, issue 2, 2019: 252-274. Published by Linköping University Electronic Press: http:// www.cultureunbound.ep.liu.se 


\section{Introduction}

Old things carry a story. Like people, things can be seen to have a social or cultural biography (Appadurai 1986; Kopytoff 1986). Old things have a character and an appeal that new things do not possess (Balthazar 2016). One way of denoting this quality is by way of patina. However, this is a rather elusive concept, which can operate in different contexts, even if not explicitly referred to. One such context is the antiques trade, which will be the focus of this article. Collecting antiques is no longer reserved for the wealthy, it has become a popular hobby among broader social groups, stimulated by television shows with a large audience like Antiques Roadshow, that can even be regarded as cult popular culture, according to sociologist Katherine Walker (2012). Antiques experts are often connoisseurs in a broader sense, and can take on different roles depending on the context they appear in, as for instance experts in antiques TV shows, as owners of auction houses, as private collectors or as writers. When experts give advice the communication form is often dialogic, both in TV shows and auction houses' collecting guides, as will be shown in this article. The main purpose of the article is to discern how notions of patina are conveyed by experts in the antiques trade. Questions that have guided me in this study are: How is patina perceived and valued in the antiques trade? How do antiques experts convey perceptions of patina to their clients and audience? How do they explain, persuade, and put forward their standards of condition? What is the appeal of things with patina?

The antiques trade is part of a second hand culture, which in turn is part of larger trend towards a more sustainable consumption. The antiques trade occupies a prominent position in the hierarchy of second hand culture, but the borders are fluent:

The relationship between rubbish and value is unclear, complex, convoluted; transfers and shifts occur between and across cultural categories which are themselves fuzzy and striated: at one end is rubbish, at the other is high (commercial and aesthetic) value, but in between are a range of possible object: value relations, gradations which include junk, debris, trash and kitsch on the one hand, and heirloom, antique and treasure on the other. (Gregson \& Crewe 2003: 115)

One case in point is retro retailing, that took off in the 1960s, and which offered for sale "objects that were quirky, unique and not well established in design hierarchies" (Baker 2012: 624). At contemporary online auctions, rusty industrial cabinets are sold alongside expensive jewellery, and goods can be shipped to clients in distant locations. Before, the sales venue, such as the retro shop, played an important role (Baker 2012), while the current second hand culture has to a 
great extent been globalised (Appelgren \& Bohlin 2015). Whereas some people feel that they lead a more sustainable life by buying second hand, other people opt to stay out of the circulation altogether, by hoarding things that would otherwise be thrown away. They regard themselves as custodians of things and attempt to use commodities to counteract consumer culture (Cherrier 2010). A more moderate stance is taken by consumers who shop second hand in order to be seen as unique and creative and to avoid the impersonal feel of goods that come straight from the factory. Buying used goods can be more demanding and require an ability to put things together and design a style of one's own, compared to buying a complete, modern style from mainstream shops (Balthazar 2016). Instead of a downward spiral of wear and decay, the circulation of goods can be seen as a process of growing, whereby things take on new meanings and qualities. They can create connections between times and places and bring out and activate memories (Appelgren \& Bohlin 2015).

The Antiques Roadshow show provides a good opportunity to examine how the discourse of patina is shaped in the interaction between experts and laymen. Antiques experts are authorities that set the note of the discourse on condition of objects. As critical multimodal discourse analysis targets power relations and authority (Machin \& Mayr 2012), it will be a suitable methodological approach to determine how antiques experts convey their norms to their clients and audience and how they explain, persuade, and put forward their arguments about the proper condition. I will analyse three main examples, a conversation from the Swedish Antiques Roadshow, a conversation from the British Antiques Roadshow and a collecting guide from Christie's auction house. The objects concerned differ in age and context of production and use, but all three examples rely on the interaction between expert and visitor/collector and give evidence of specific attitudes to patina, although in different media. The first two examples are film clips from TV shows and the third example is a web page with text and images. Multimodal analysis is suitable for the audio-visual media that forms the core of the material of the study. As a visual studies scholar, I will pay attention to gestures, body language, gaze, but also to tone and level of voice, and different linguistic markers. Apart from the shows themselves, I have made use of books and online magazines about Antiques Roadshows.

The discourse on patina is made up of many statements in different media, which is why a mix of methods is necessary in order to capture this discourse. My material also consists of two interviews conducted in 2017 with antiques dealers, one with a manager at a major auction house and one with the owner of an online auction site, both with long experience from the antiques trade. When visiting the auction house, I also made observations and took photographs of the display of goods. Notes were taken during interviews and observations. Another category of 
material that I have consulted and that is important for the understanding of the discourse on patina is the diverse range of publications such as newsletters, online discussion forums, essays by furniture restorers, and auction house websites. Together with the interviews, these publications serve as voices from the trade.

\section{The concept of patina}

According to Merriam-Webster Dictionary, patina is defined as

1. a usually green film formed on copper and bronze by long exposure or by chemicals and often valued aesthetically

2. a surface appearance (as a coloring or mellowing) of something grown beautiful especially with age or use

Although patina originally applied to metals, it is the second, broader definition of patina that will be used in this article.

If we turn to an actor in the antiques trade, a furniture restorer gives the following explanation of patina on their web page:

What is a patina? A patina is a natural change to the surface of an object caused by oxidization, sunlight or dust/dirt. Patination is considered to be an unavoidable change to a piece as compared to an accidental stain such as that caused by spilling something on the item. Patination helps tell the story of an item and, as such, adds value. (Rahn's Furniture Restoration 2015)

Michael Flanigan, an antiques dealer and an Antiques Roadshow appraiser in the American version of the show, is cited by freelance writer Dennis Gaffney, in one of his articles for the Antiques Roadshow online:

"Patina is everything that happens to an object over the course of time," Michael says. "The nick in the leg of a table, a scratch on a table top, the loss of moisture in the paint, the crackling of a finish or a glaze in ceramics, the gentle wear patterns on the edge of a plate. All these things add up to create a softer look, subtle color changes, a character. Patina is built from all the effects, natural and man-made, that create a true antique". (Gaffney 2008) 
From these examples of definitions, we can infer that patina is a positively charged concept, as expressed by "valued aesthetically" and "beautiful" in the dictionary definitions and the reference to story-telling that adds value, in the restorer's definition, and the choice of words such as "gentle" and "true" in the American antiques dealer's description. Condition reports in auction houses tend to emulate the style of museum condition reports, which aim to be objective and devoid of subjective opinions and vivid descriptions. In an interview with a middle manager at a major Swedish auction house, I learnt that the term patina is not used by the specialists of the auction house when cataloguing and writing condition reports about objects, since it is regarded as too sweeping a characterisation.

In an academic context, research on patina relevant for this article has been conducted by a number of anthropologists (McCracken 1988, Miller 2009, Dawdy 2016). Grant McCracken (1988) explains the workings of the patina system of consumption and how it conveyed status from medieval times until the fashion system replaced it in the $18^{\text {th }}$ century when the consumer society evolved. Before the $18^{\text {th }}$ century, possessions of families of high standing were handed down to new generations and in the process these objects became worn, chipped and dented. Their transformation was physical, but above all patina served as a symbolic asset, legitimising the status of the family. In the new consumer society, the pace of fashion accelerated and new objects were valued higher than old, inherited object. "With novelty in the ascendent, patina fell into eclipse" (McCracken 1988: 32). In the modern world, patina still exists, but leads a more obscure life, used only by the nouveaux riches who buy objects with patina to assert their status. McCracken concludes: "For the mass of society, the notion of patina is hopelessly antique, a charming notion that has passed from fashion" (McCracken 1988: 43). Consumer society has changed since the 1980s, and one could argue that through second-hand culture, patina is on the rise again.

Daniel Miller (2009) approaches the subject of patina by comparing the business of distressed jeans with the market of second-hand goods. The jeans have never been worn by a person but have gone through an industrial process to look worn and to acquire a patina. The junk and antiques that one can find in flea-markets and other informal outlets, on the other hand, have been used and worn by real people. While the jeans are primarily consumed by young people and the flea markets are frequented by the older generation, Miller regards both cases as a way of buying time, as "a trade in patina" (Miller 2009: 142). The important thing is not that we ourselves have used these things, but that we, in these different ways, take part in the circulation of generic lives (Miller 2009).

Patina as a concept can also be applied to a whole city, as Shannon Lee Dawdy (2016) does when discussing the effect of the Hurricane Katrina on the city of New Orleans in 2005. The reconstruction of the city has given rise to questions 
of authenticity and how to manage the cultural heritage and the patina for which New Orleans is famous. The city has a strong grip on the past, that few other American cities can rival. In addition to bigger urban structures, Dawdy pays attention to the great interest for antiques shared by many citizens of New Orleans. She has interviewed people who lost their houses in the hurricane, and they point out heirlooms as the objects they miss the most. Such heirlooms are often regarded by their owners as worthless from a financial point of view, and they seldom enter commercial circulation. There is also a flourishing antiques market in the city, where collectors are hunting for rare items and tourists are buying souvenirs. Dawdy argues that "patina does two important things. It critiques the present in general and capitalism in particular, by creating a heterotopia of an 'other time'. And it helps bind people together by providing an everyday sign of fictive ancestry and collective affect - a profane kind of mana" (Dawdy 2016: 18).

Judging from the findings of these three anthropologists, patina is a malleable concept, which has taken on many different meanings in different times and contexts. It is at present not "hopelessly antique", rather positively antique, and can be used to define our relationship to the past and the passing of time as seen through material culture. Whereas Dawdy sees patina as critiquing the present and capitalism, it could also be argued that it is because the concept is nebulous and has too many positive connotations, that it is scarcely used by the experts in the auction trade, who want to inspire credibility and trustworthiness as experts in general, not just agents of the companies they represent. The Antiques Roadshow is an arena where they can perform this role.

\section{The Antiques Roadshow}

The British version of Antiques Roadshow was launched in 1979 and the format has since spread to several other countries. People are invited to bring their heirlooms or flea market finds to the show and have them evaluated by experts. Still, between 1500 and 4500 people are prepared to queue for the chance of participating in an episode (Atterbury \& Allum 2017: 12). When the Swedish Antikrundan first aired in 1989 in cooperation with BBC, some episodes were filmed in Scandinavian cities, with British experts. In 1990, Swedish experts had been recruited. The program is still running and is one of the longest running programs of SVT (Sveriges Television). The format has stayed the same but some changes have occurred and the program has moved with the times. "The most important change has been a gradual shift away from antiquities and their values towards the owners and their stories" (Atterbury \& Allum 2017: 15). In the opinion of Hugh Scully, one of the first British presenters, the most memorable feature of the program was the encounter with the owners, many of whom represented the eccentric British 
character (Atterbury \& Allum 2017: 10). Both in the UK and in Sweden the experts have become popular TV-personalities. The book Antikrundan: värdefulla råd och dyrköpta erfarenheter (The Antiques Roadshow: valuable advice and dearly-bought experiences) (von Platen \& Tull 2005) devotes one chapter to each expert, the chapter title consisting of the name of the expert and hers or his area of expertise.

The experts are not allowed to purchase or make any offers for the objects they appraise in the program. Nevertheless, the show has a symbiotic relationship with the market. This fact was highlighted by the owner of an online auction site, when I interviewed him. In his opinion, the program has been decisive for the antiques trade, by creating an interest in antiques. The experts are dealers, which influence their appraisals. By way of example: if a dealer has bought a bureau for $4000 \mathrm{kr}$ and spent money on restoration, transport etc, he might sell it for $22000 \mathrm{kr}$ in his shop. That is the price, the owner of the online auction site explained, he then tells the owner, not $4000 \mathrm{kr}$, in order to be able to sell his bureau for the higher price.

Although the program has a strong commercial aspect, it is also a form of public education, teaching cultural history through objects (Janson 2000). The Swedish program is now mixing appraisals with short features with information about periods, artisans and artists. The program conveys standards of condition, how to care for antiques, how to detect forgeries, in sum, it educates consumers to become more discerning antiques buyers and owners.

\section{The surface and the object beneath it}

In his essay "Surface visions", Tim Ingold proposes that we should pay attention to the mundane surfaces that we encounter in everyday life, for instance water, stone, cloth, skin and paper, and also the gestures we use to treat these surfaces: "washing, scrubbing, brushing, sweeping, raking, shaving, ironing, mowing, polishing, scraping, grinding, and much more. These are operations that turn rough into smooth, dull into shiny, opaque into transparent, written scrawl into blank slate" (2017: 100). I think this is an eloquent way of describing the process of patina.

Patina is often, in the examples of definitions in the previous section and elsewhere, referred to as a surface phenomenon. One of the experts in the Swedish Antiques Roadshow says he is attracted by furniture that have retained the original paint, but that it is not about the paint, but the surfaces. "It is the traces after 200 years of use that form a link to history" (Janson 2000: 49). He thinks that the connection to the past is cut off if a piece of furniture is re-painted or the paint is removed. The restorers of the best preserved $18^{\text {th }}$ century theatre in the world, Drottningholm Palace Theatre in Stockholm, have a similar view: 


\section{Culture Unbound}

Journal of Current Cultural Research

When you enter this time capsule there is a smell of the 18th century. It is quite worn and there is a patina that we try to take care of which is very Swedish. In other countries, the form is valued, but here we value the worn surface as well, the slowed down ageing process. Especially the 18th century we treat with utter care, which means that we try to preserve the upper layer. (Volpe 2010: 32)

Is patina part of the object or separate from it? Can the object be seen as intact under the surface? Furniture can have a sanded, painted or gilded finish, and the smoothness of the finish is an important aspect when assessing the quality of a piece of furniture. Finish can be seen as a cover that encloses an object and makes it into a perfect whole. Patina punctures this perfection of the object - wear and crackles make the object vulnerable and give us a glimpse beneath the surface. If when the object was brand new, we focussed on the surface, patina becomes the double focus lens that allows us to focus both on the surface and the core of the object. Depending on the object, the core can have different compositions, it can consist of one massive material like wood or metal, or it can be made up of a structure with several different materials connected through that structure. In 3D computer graphics, which constitute the visual environment in most computer games, objects are constructed as shapes made up of polygons, and then different textures can be mapped onto the shapes. In the physical world, there is no sharp line between surface and core, it is a continuum. Nevertheless, for the sake of clarity, the surface - core relationship will be a useful conceptual tool in the analyses.

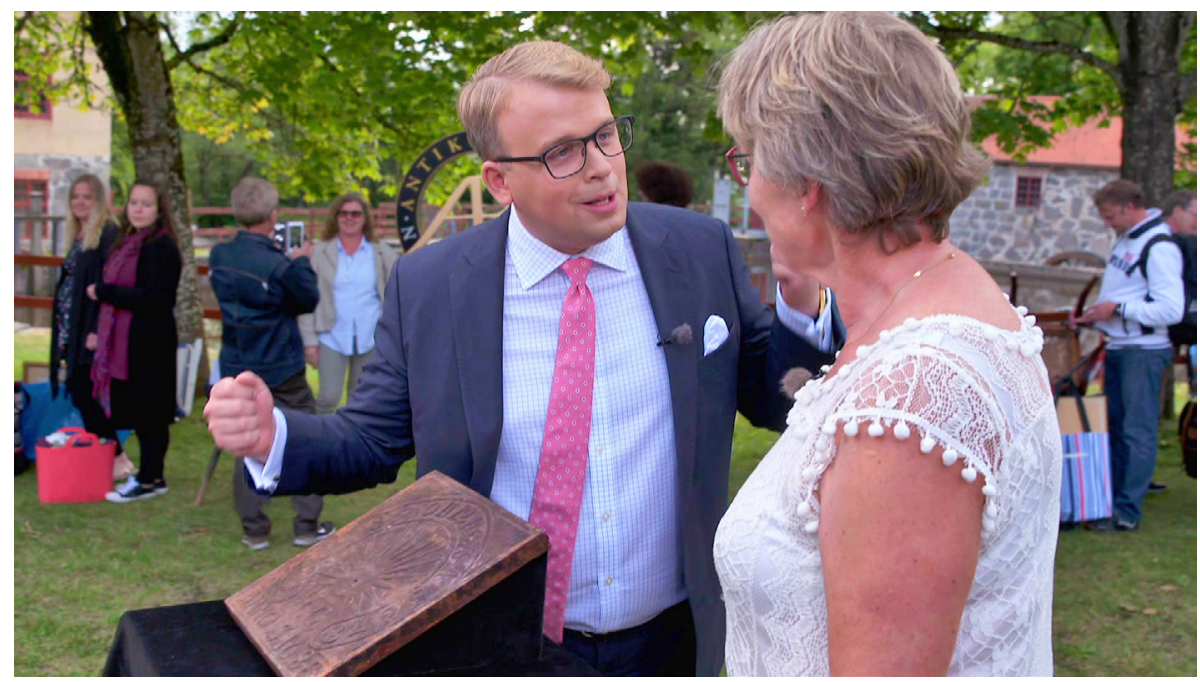

Figure 1. Conversation about sundial from the Swedish Antiques Roadshow @ SVT Antikrundan. 


\section{The sundial with the missing stick}

In one of the episodes of the Swedish Antiques roadshow (season 29, episode 1, 2018), a visitor had brought with her an old cast iron sundial that had lost its stick. The format of the sundial was square, and the year 1688 appeared on the face along with the initials KGS, which stands for the nobleman Karl Gustav Sparre. The expert asks the visitor what she knows about the object, and as she seems to be quite knowledgeable about it, he wonders why she came to the show.

V: Well, because I would like to know how to renovate it. (laughs a little)

E: Are you going to renovate it!! (exclaims, surprised and upset)

V: No, but I have to have a stick there for otherwise I can't see the time, can I? (points to the middle of the sundial)

E: Okay, I'm getting really worried. You'll be renovating it, and if we start by confirming that this is an original, it's made in 1688 , so everything is correct and I think it's a wonderful sundial. 18th century sundials, we get them at every location in the Antiques Roadshow, they are even quite common.

\section{V: Okay}

E: But when you step back into the 17th century, it's the period when Sweden was a great power, during the baroque, really. I think it's wonderful just as it is and you might think it's rusty, and so on. There is only one thing you are allowed to do, you can take linseed oil and gently grease it, to prevent further oxidation, I really don't want you to do anything else. You must not blast, paint or do anything else (lectures with emphasis, raises his voice in the last sentence).

V: But what about the stick then?

E: Then it's ruined!! (says emphatically, raises his voice)

V: The stick? (says questioningly)

E: Destroyed!! (makes gesture with his hand) 
V: (Laughs a little startled)

E: Let it be!

V: Yes, but I can't tell the time.

E: Get yourself a clock. (gesticulates with his arms) I think it's wonderful, you have the whole story and it's in a great condition, it's not cracked or anything, I think the condition is good.

V: Okay

E: I want you to think that the condition is good. (takes a step towards her)

V: (laughs)

E: But you didn’t buy it, did you?

V: No, I found it, I was going to clean an outhouse, and it just stood there, it just came with the farm when I bought it.

E: Fantastic. Value, provided you don't destroy it. (says sternly and encouragingly) What kind of money are we talking about, do you think?

V: No idea, I think....

E: It is after all the period when Sweden was a great power.

V; Yes, but I don't think....

E: Now the Caroline collectors emerge, they sort of like the baroque thing.

V: No, I don't have a clue.

E: I believe that if we find a number of collectors, the market value would probably be about $15000 \mathrm{kr}$ (£1200). 
V: Okay! I wouldn't have guessed that. Fantastic find. The farm became less expensive in this way. (laughs)

E: Just pay off the mortgage. (laughs)

The price is probably not the reason why this object was selected for inclusion in the final show. 'We pay great attention to the owner's reactions during the conversations and the moment when the price of the object is revealed', says the producer of the Swedish show (Janson 2000: 41). What makes this conversation interesting is the tension between the expert and the visitor, created by a different notion on the general value of the object in question. The visitor regards the object as a clock, a utility object that can be used to tell the time, and she expects to get some advice about how to make it function again. The expert sees a rare object that has once been a utility object but is now valuable foremost as a trace from the past. His mission is to prevent her from doing any harm to this historic object and to instil in her the correct perception of patina. The expert and the visitor are not on the same wavelength, and the little controversy that ensues creates tension and excitement, which is of value for the show.

It is the expert who has the upper hand in this attempt of persuasion, since he is the authority on antiques, but the visitor does not yield voluntarily. She raises objections and brings the stick repeatedly into the conversation, and she looks incredulous and not entirely convinced when the expert fastens his eyes on her and tells her to get a modern clock if she wants to know the time. He makes big gestures and he transgresses her personal space to emphasise his standpoint. $\mathrm{He}$ uses modal verbs of obligation and prohibition, such as must, and he also asserts his authority by telling her what she thinks, that the object is rusty and in a bad condition. The expert plays both roles in order to persuade the visitor that her point of view is wrong, and points out the advantages of the object's current, patinated condition. We do not need this object to tell the time, other more modern contraptions have been invented since the late $17^{\text {th }}$ century. What we need is an old, patinated object that remind us of our history. The stick is not an indispensable feature of the sundial in order for it to serve that purpose. If the sundial would be restored and fitted with a new stick, it would be altered in a way that severs the connection to the past. The behaviour of the expert can seem a little harsh, but he has to persuade not only the owner of the sundial, but the whole audience watching the show on TV. The conversation has a persuasive purpose and enacts a common trope in the show: the expert who saves the object from its owner's neglect and ignorance.

An iron tablet is a massive object with no structural difference between the surface and the core. However, oxidation can make the whole object vanish if rust 
is let to eat away layer after layer of the tablet. The only measures the owner is allowed to take is to grease it with oil, in order to stop the decay. This is somewhat paradoxical - patina is desirable, but only to a certain extent. The process should not be allowed to continue, because then there is a risk that it will ruin the object. The tension between the expert and the visitor described above can be construed in terms of functionality and patina. The visitor is focused on the functionality of the timepiece, whereas the expert assumes that she is deterred by the rusty, patinated surface. If he had been able to put himself in her shoes, it would have been easier for him to win her over for his cause.

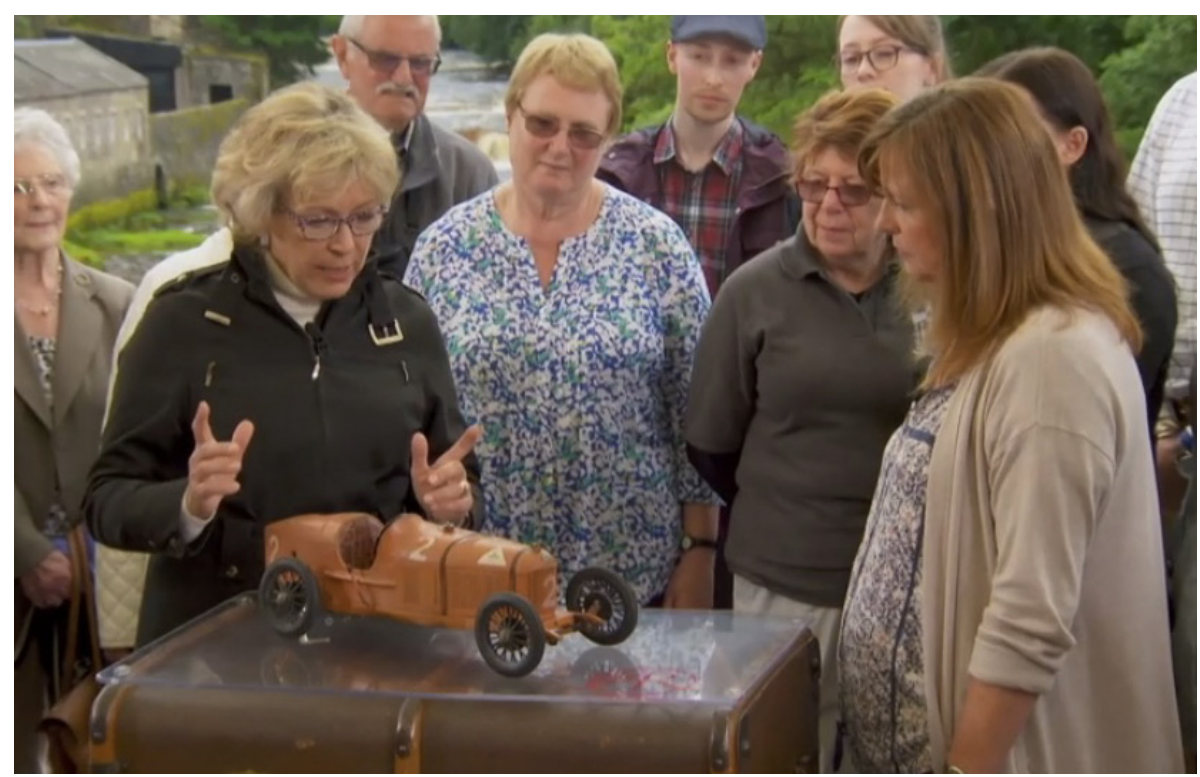

Fig 2. Conversation about toy car from the British Antiques Roadshow (c) BBC One Antiques roadshow.

\section{The play-worn toy car}

A different approach is taken in this conversation from the BBC Antiques Roadshow (series 39, New Lanark 1, 2017) about the toy car P2 Alpha.

E: This is such a great toy car. It's big, it's bold, it's beautifully decorated, it's a snazzy colour. Why have you got it?

V: Oh, my husband got it as a gift from his grandmother when he was on holiday, and he would have been about seven, so about forty-three years ago and she bought it at a jumble sale, they were at the beach, she 
went off to a jumble sale and came back with the car for him. He was quite delighted with it!

E: I bet he was, presumably just bought for a few pence!

V: Yeah, it was I think 10p, 20p, something like that, certainly not anything. It was a jumble sale in Millport, so... Nothing would have gone for a lot of money there.

E: Presumably, it had been played with and was in poor condition when he got it?

V: Well, no, no it wasn't. He got it and he played with it, he had his action men in it and it was up and down the street and he had a lot of fun with it.

E: I suppose, an object can only give once, yeah.

V: Yeah

E: And it's already given, and it's given a lot of pleasure to your husband. But to me, almost, it's too good to be a toy. For lots of reasons, let's just have a look at how beautifully made it is. First of all, it's modelled on a real car.

V: Yeah

E: It's modelled on an Alpha Romeo racing car called a P2, so it's known as the P2 Alpha. And just look at the detail. First of all, the filler caps, just below the cockpit and on the radiator, the radiator grille, the tyres, they're proper cars' tyres, they say Michelin on them. And the exhaust, the hand break, the actual, proper, usable steering wheel. So, in every way it looks like the real car, apart from back here, where of cause, you've got the arbor to wind up the clock work, not seen on the full-size vehicle. (laugh) It was made in France, by company Compagnie Industrielle du Jouet (CIJ), and the P2 Alpha was the car at the moment, in 1925 it won an important race, and it was the formula 1 car of its time, so that's why the company produced them, it was riding a wave of popularity, and they produced a whole range of these in different colours, so there was silver and white and red and blue, and, the orange one is 
an unusual one.

$\mathrm{V}: \mathrm{Oh}$

E: So, let's think about the little boy that would have owned this in the 1920s, he would have been from a good family, he would have probably heard about this fabulous race where the P2 Alpha had won, and he would have got this at Christmas and would have been completely over the moon. So, your husband, eh, had a lot of fun with it, and has it been passed down through the family or?

V: Oh yeah, now it sits on a ledge in my son's room, so he enjoys it, thinks it looks quite cool, so (laughs).

E: Cool it does look. What's it worth?

V: I don't know.

E: I would have said, year after year after year, these were fetching $£ 2000$, which is a lot of money for a toy car, and I was very excited whenever I saw one of these. As a result, something very strange happened this year, and one sold for $£ 12000$, so that has now made me completely rethink the value of this. I mean, admittedly the one that was sold earlier in the year was in perfect condition, original condition, this isn't, but actually, I like the fact that it has been play-worn, it doesn't worry me at all, and it won't worry some types of collectors. So, I think that I'm going to have to look at that $£ 12000$-price and look at the regular price, and put it somewhere in the middle, so I would say that your car today would be worth between $£ 4000$ and $£ 6000$.

V: Oh dear, well I never expected that, not at all. (laughs surprised)

E: And is your son still going to have it?

V: Yeah, I think so.

E: Lucky son! Well, thank you very much indeed for bringing it in, it's been a real treat. 
V: Thank you, thank you very much. I'll get it back in the bag. (laughter from audience)

The interaction between expert and visitor in this conversation is built on cooperation rather than tension. Both contribute to spinning the story of the old toy in its different life phases and transactions, which is a salient feature of the show (Walker 2012: 23) However, the expert has the initiative and is the driving force in the conversation. She gives the visitor general information about the car and when, where and why it was produced, and underlines her statements with big gestures directed at the car. The visitor listens attentively, and uses back-channel signals like nods and giggles, in response to what the expert says. For her part, the visitor possesses crucial information about this specific car and can contradict the expert's assumption that it was in poor condition when her husband got it, and she assures the expert that he played with it outdoors and had a lot of fun with it. The present condition of the car is presumably the result of at least two children's play, the first and the second owner of the car. The term the expert uses is 'play-worn', which indicates an agreeable form of wear, with positive connotations of childhood, in which the viewers and experts alike can indulge.

The expert praises the car and its qualities and elevates it to a 'serious' artefact by stating 'But to me, almost, it's too good to be a toy. When it is time for the appraisal, the expert conducts a line of argument that indicates that there is a change in the attitude towards patina in the antiques market and that the worn condition is now more highly valued than before. The expert gives details about the price trend in toy cars and how a car of the same type was sold for a much higher price than usual. That car was in a pristine condition, but she says: 'I like the fact that it has been play-worn, doesn't worry me at all, and it won't worry some types of collectors.' The reason given for the increased price level is thus the preference of the collectors, not some external factor on the market. However, she is a little cautious, shown by her use of the word 'worry' twice in the sentence above. The idiom 'don't worry' is frequently used to reassure people that everything is alright, but nevertheless it suggests that there might be something to worry about.

Patina resides on the surface of the toy, but ageing does not seem to have affected the core of the car. Were it not for its newly assigned monetary value, it would be fit for more play. Unlike the sundial in the previous example, it does not lack any vital part of its structure and still has the potential to fulfil its original purpose. In this case, there do not seem to be a conflict between patina and function. It is also not as old and rare as the sundial, it is an industrially manufactured $20^{\text {th }}$ century object, and many similar copies might still exist, although this colour is unusual. The process of patina can be allowed to continue, it does not have to be stopped at this exact moment in time. 
The reasoning of this expert is in line with other actors in the antiques trade. Alessandro Pergoli Campanelli, researcher in heritage conservation, published a short piece on the value of patina in News in Conservation, a newsletter from the International Institute for Conservation of Historic and Artistic Work. He claims that there is a change in the perception of patina in the market, and puts forward the example of vintage wristwatches: the ones with an original, worn dial have become more valuable than watches with a reprinted dial (Pergoli Campanelli 2012). Other experts share this view, for instance Eric Wind, one of Christie's watch experts, who in the piece "Aged to perfection - The patina trend in watches" states that "This trend towards seeking honest patina has extended worldwide, particularly over the last five years" (Wind 2017).

\section{Vintage watches and the tooth of time}

This example is part of the auction house Christie's website, a collection guide where Christie's experts give advice to collectors and buyers, published $27 \mathrm{Fe}$ bruary 2015. The title is Ask a Specialist: Value vs. Condition. The preamble reads "Don't polish that case! Christie's Watch Specialists on why it's best to keep your watch all original” (Christie's 2015).

Unlike the previous two examples, this is not an oral dialogue between two individuals. The text has the narrative form of Questions and Answers, which is frequent on websites. No names are mentioned, the question is preceded by "Q:"and the answer by "A:". The text contains frequent references to watches sold by Christie's and also three images of Rolex watches, two of which are examples of how patina can enhance the value of a watch.

The opening question is 'When is a little wear and tear too much? Is it ever a good thing?' and the rest of the text is a long answer that covers different aspects of this question. The unused, unworn watches in pristine condition are still the most valuable, but a change towards higher appreciation of patina is underway. From the outset it is clear that the aim is to convince the inexperienced collector, who might avoid worn objects, to realise the value of watches with patina. The structure of the text is based on the parts of a watch, such as bezel, dial, case, crystal, bracelet and movement. We get to know that bezels made of the brittle material bakelite in the 1950s and 1960s are rare and have been replaced in most watches of the time, which is why original bezels are valuable even if they are faded or cracked. Dials that are faded in the right way are also sought after.

The hottest word in vintage watch collecting right now is "tropical," which essentially means something has faded because of the sunlight. The paint on the dials, for example, can fade. That does create more 
value in many collectors' eyes. And it also shows use, which gives a watch a story. It hasn't just been sitting on the shelf. That's particularly appealing with vintage Rolex sport watches which could have been used anywhere from a racetrack to a mountaintop to a deep sea military excursion. (Christie’s 2015)

The attraction is reduced if the fading is uneven. What collectors are looking for are watches with "consistent patina". Some collectors like the effect of cracked lacquer, but it depends on their personal taste. When cases are concerned, they should not be polished. In 2011, Christie's sold a rare watch that was nearly black by oxidation, which was a sign the watch was virtually unused, and it went for a high price. A badly scratched crystal may be replaced as may the bracelet, as long as it is one from the same manufacturer. Finally, the movement of the watch should be in good condition. Function is essential, as expressed by the statement "The watch should work" (Christie's 2015).

This text is characterised by vivid description of the watches and their different parts, especially the surfaces. The accounts of the watches sold by the auction house are rendered in an anecdotal and conversational tone, to make the reader feel she is listening to the advice of an expert in person. To create the illusion of dialogue, fictive quotes from collectors are inserted, for instance "It might make a collector say 'I don't want anything to do with it." (Christie's 2015) Advice is given, but not with absolute certainty. Modal verbs like might, can, and modal adverbs like sometimes, often, are used throughout the text, and phrases like "But again, there's a balancing act" indicate that the discourse on value is an ongoing negotiation and the criteria are subject to change.

The surface - core relationship is more intricate in the case of watches than in the previous two examples. There are several surfaces that have to be reckoned with and the core of a watch is made up of a complicated mechanical clockwork. Full functionality is a prerequisite, and a fine patina cannot compensate for a deficient measuring of time. The case can be opened and the clockwork inspected, but under normal conditions, the core of the object is hidden from view and should be protected by the outer parts of the watch.

\section{How different attitudes to patina are conveyed}

Taken together, what do these three examples tell us about the notions of patina? For the antiques programming, the dynamics between different norms and valuation of condition of objects can be seen as a benefit, as it adds drama to shows like the Antiques Roadshow. For auction houses, a higher valuation of worn objects entails an opportunity to expand the market and for collectors it means a challenge 
to their prevailing taste and preferences.

The experts use different persuasive strategies to convey their norms regarding the condition of objects to their clients and audience. The strategies all build on references to the collectors and their tastes. In the case of the sundial, the expert says "Now the Caroline collectors emerge, they sort of like the baroque thing", as a hint to the visitor about the price. The toy expert assures that the play-worn condition "won't worry some types of collectors" and the watch experts frequently refer to the taste of collectors in their advice. The most common persuasive strategy is reference to sales prices at auctions where similar items have gone under the hammer. The toy expert is the only one who explicitly brings up a shift to a higher price level for toy cars with patina, which surprised her, and which is why she dares estimate this particular car at a higher price than she would have before.

The role of the expert is close to that of a teacher, and therefore it would be relevant to talk about didactic styles when analysing how the experts convey their norms of the condition to their clients and audience. The sundial expert applies a stern, schoolmasterly style when talking to the visitor. He states how it is and expects her to obey his advice regarding the care of the object. The toy expert uses a gentler tone, and conducts a line of argument about recent auctions sales in order to convince the visitor. The watch experts have the smoothest didactic style, probably because they want to keep the door open to all sorts of clients. Even though they stress the value of watches with patina, they bring up several cases and take pros and cons into consideration.

\section{Use and usefulness}

Usefulness must be seen in relation to age. The sundial is too old to be expected to have any use value, and should not be restored. It is seen by the expert from a conservation perspective, where the goal is to keep it from further deterioration and where only minimal intervention is recommended (Hölling 2017, Jones \& Yarrow 2013). Different principles apply to newer utility goods, that should be fit for use, according to both the manager at the auction house and the owner of the online auction site that I interviewed. "To customers who ask if they can repaint a $20^{\text {th }}$ century kitchen table, I would say, go ahead" said the manager. She thinks that simple objects are utility goods and should be used in a home. However, one should not repaint the bronzing of an antique mirror. The owner of the online auction site stated that "If I buy a chair, I want to be able to sit on it, if I buy a castiron bowl, I will use it for keeping my keys". The extra wear that will be result does not affect the monetary value of the objects. I perceived in the interviews a certain resistance to the reverence of the "original condition", that Antiques roadshow have fostered. What is relevant for older and rare antiques are not necessarily applicable 
to modern antiques and vintage goods.

Walker points out that we would not by a million-dollar card table in order to organise a poker night with friends, even if the table would still be fully functional. Such use could affect its value. "Rare and highly collectible items are not bought to be used, especially if use would somehow alter their condition. Action figures still in their original packaging are highly collectible and fetch high prices on the market, but as toys, they are completely useless" (2012: 21). However, there are different forms of use, and Walker adds that a collectible is "put into symbolic use every time its owner gloats over it or admires its beauty" (2012: 22). This means that the action figure in its pristine condition is still being used, but not in the same way as the toy car, that had been out on the streets and played with. Worn toys carry positive connotations to childhood and the freedom of being immersed in play. Aged and used Rolex sport watches carry connotations to adventure, masculinity, and advanced technology. Both objects tell a story through their patina. "If I wanted something that looked new, I would just go into a boutique and buy it. But I wanted something different; a watch that has been made unique by the ageing process" a young collector told a Christie's watch expert (Wind 2017).

\section{Humans in the material world}

The watches in Christie's collection guide provide a complex case of patination, in that they have been in close contact with human skin, sitting on the arm, as well as undergone a chemical process that man cannot influence. A watch is made up of several surfaces, some exposed to human touch and others, like the dial, that is enclosed and out of reach for human touch. Sunlight can fade the dial and create a "tropical" effect. Defect lacquer can result in cracks looking like spider web. Humans do not control these processes, but human connoisseurs decide whether the kind of patina is advantageous or not (Christie's 2015, Omega forums 2017).

The sundial has undergone a natural chemical process of oxidation, due to age and exposure to the elements. It is not human touch, not the gestures that Ingold mentions in his essay "Surface visions", that have altered the metal surface. In his discussion article "Materials against materiality", he examines some attempts made by researchers to overcome the mind - matter polarity, and ascribes their lack of success to "the slippage from materials to materiality" (Ingold 2007: 7). Ingold advocates a focus on materials instead of on materiality, a term he thinks has contributed to skewing the discourse on material culture and further distanced us from materials. Humans are part of the material world and the human body is made up of materials like blood, skin and bone. "Like all other creatures, human beings do not exist on the 'other side' of materiality but swim in an ocean of materials" (Ingold 2007: 7). 
Maybe objects with patina are popular because we feel an affinity with them. Using concepts like "the social life of things" and "cultural biography" is a way of humanising things and bringing them closer to us. If a thing has a life trajectory, it will also involve ageing. In the literature on antiques, there is a tendency to draw an analogy between the ageing of human beings and artefacts. Writing on the condition of antiques, the philosopher and heritage scholar Leon Rosenstein states:

As is the case in human physiology, there are two sources of an object's deterioration. The first is genetic: the material breaks down and slowly decomposes, especially in the case of organic materials (cloth, wood, oil paint). The second source of deterioration is accidental (traumatic): damage is by external forces such as wear, stain, breakage, and erosion. (Rosenstein 2009: 165)

"Organic materials" can refer to both humans and artefacts, and damage, if happening to a human, is not only accidental, but also traumatic. In a book on how to decorate with vintage finds, an analogy is drawn between the imperfect object and the imperfect human being:

Old things carry histories, they last long and they smarten up all that light and fresh that we think we have to live among. Besides, the chafed and odd things are more forgiving. They make us justice, show us that also the worn is okay. No man is perfect. No man is made in an assembly line according to a check-list. We carry with us our background, that betray who we are with the help of scratches, scars and personality. In the same way, your home does not need to be perfect. It is a mirror of you, who you are and how you like to live your life. (Billgren 2014: 92)

Here we find patina as metaphor for human imperfection and as a means for taking a stance against the prevailing norms for appearance. According to the writer, these things create a friendly environment and allow us to feel at home with flaws and all. Patina is thus not a one-way process, where we give objects patina while using them, but objects can also influence us and the way we see ourselves.

\section{Conclusion}

What I have shown in this article is how vital the discourse of patina is for the antiques trade. A TV show like Antiques Roadshow is an ideal arena for the dissemination of notions of condition and patina. The expert in the sundial example tells the visitor with emphasis: "I want you to think that the condition is good". By 
such statements, experts influence not only visitors and audience, but the whole antiques market. The way patina is perceived in the antiques trade vary over time, depending on the age and category of the object. Different attitudes can co-exist, as long as there is a demand from collectors.

Before the $18^{\text {th }}$ century, when the patina system still ruled, patina gave status to a certain family through the passing down of heirlooms (McCracken 1988). Commodities sold at flea-markets can be characterised as tokens of a generic past, because they are circulated so frequently that they lose their connection to the original owner (Miller 2009). Reuse in a circular economy means passing things on to somebody else, but not necessarily to another family member. The toy car is a case in point.

According to McCracken, patina had to cede as a status marker to the fashion system in modern consumer society (1988). Since the 1980s, the pace of fashion and consumption in general has accelerated. Instead of trying to keep up with this pace, buying antiques and second-hand goods can be a way of slowing it down. Owning and using utility goods with a patina can be seen as a critique of an unsustainable consumption of brand-new things that have required new resources to be produced.

Apart from the rise of sustainable consumption as an explanation of the popularity of things with patina, another factor can be brought forward. We see antiques and other second-hand objects as mirrors of ourselves, and by surrounding ourselves with such objects, we find a way of reconciling ourselves with our own ageing process, and realise that the valuation of old age is not static. In circulation, second-hand objects move up and down along the hierarchy. What is today regarded as a shabby piece of junk may tomorrow become elevated to an antique with fine patina.

Karin Wagner is a professor in Art History and Visual Studies at the Department of Cultural Sciences at the University of Gothenburg, Sweden. Her research interests within visual and material culture include photography, new media, and visual communication. A recent article is "Nostalgic photographs in the contemporary image ecology: the example of Tyrrells crisp packaging", Journal of Aesthetics \& Culture, 2018, 10 (1). E-mail: karin.wagner@gu.se

\section{Notes}

${ }^{1}$ This and the following quotes from Swedish texts are my translations. 


\section{Culture Unbound}

Journal of Current Cultural Research

\section{References}

Antiques Roadshow (2017): TV show, series 39, New Lanark 1, BBC.

Antiques Roadshow (2018): TV show, season 29, episode 1, SVT.

Appadurai, Arjun (1986): The social life of things: commodities in cultural perspective, Cambridge: Cambridge Univ. Press.

Appelgren, Staffan \& Anna Bohlin (2015): 'Growing in Motion: The Circulation of Used Things on Second-hand Markets, Culture Unbound: Journal of Current Cultural Research, 7(1):143-168.

Atterbury, Paul \& Marc Allum (2017): Antiques roadshow - 40 years of great finds, London: HarperCollins Publishers.

Baker, Sarah Elsie (2012): 'Retailing retro: Class, cultural capital and the material practices of the (re)valuation of style', European Journal of Cultural Studies, 15:5, 621-641.

Balthazar, Ana Carolina (2016): 'Old things with character: The fetishization of objects in Margate, UK', Journal of Material Culture, 21:4, 448-464.

Billgren, Elsa (2014): Inred med vintage (Decorate with vintage), Stockholm: Bonnier fakta.

Cherrier, Hélène (2010): 'Custodian behavior: A material expression of anti-consumerism', Consumption, Markets and Culture, 13:3, 259-272.

Christie's (2015): Ask a Specialist: Value vs. Condition, https://www.christies. $\mathrm{com} /$ features/Vintage-Watch-Original-Replacement-Damage-Ask-A-Specialist-5722-1.aspx (accessed 1 August 2018).

Dawdy, Shannon Lee (2016): Patina: A profane archaeology, Chicago; London: The University of Chicago Press.

Gaffney, Dennis (2008): What "Patina" Really Means, http://www.pbs.org/wgbh/roadshow/fts/lasvegas 200706A35.html (accessed 27 June 2018).

Gregson, Nicky \& Louise Crewe (2003): Second-Hand Cultures, Oxford: Berg.

Hölling, Hanna (2017): 'The technique of conservation: on realms of theory and cultures of practice', Journal of the Institute of Conservation, 40:2, 87-96.

Ingold, Tim (2007): 'Materials against materiality', Archaeological Dialogues, 14:1, $1-16$.

Ingold, Tim (2017): 'Surface Visions', Theory, Culture \& Society, 34:7-8, 99-108.

Janson, Bengt (2000): Antikrundan: programmet, experterna, föremålen (The Antiques Roadshow: The Program, the Experts, the Artefacts), Stockholm: Prisma.

Jones, Siân \& Thomas Yarrow (2013): 'Crafting authenticity: An ethnography of conservation practice', Journal of Material Culture, 18:1, 3-26.

Kopytoff, Igor (1986): 'The Cultural Biography of Things: Commoditization as Process', Arjun Appadurai (ed): The Social Life of Things: Commodities in Cultural Perspective, Cambridge: Cambridge University Press.

Machin, David \& Andrea Mayr (2012): How to do critical discourse analysis: a multimodal introduction, London: Sage.

McCracken, Grant (1988): Culture and Consumption: New Approaches to the Symbolic Character of Consumer Goods and Activities, Bloomington, Ind.: Indiana Univ. Press.

Miller, Daniel (2009): 'Buying time', Elizabeth Shove, Frank Trentmann \& Richard Wilk (eds): Time, Consumption and Everyday Life: Practice, Materiality and Culture, Oxford: Berg, 157-170.

Omega forums (2017): Tropical 2998-2, https://omegaforums.net/threads/tropical-2998-2.56494/ (accessed 1 August 2018).

Pergoli Campanelli, Alessandro (2012): 'The value of patina on the antiques market Affinities and relationships between conservation theories and buyers' taste', News in Conservation, 31, 8-9.

Rahn's Furniture Restoration (2015): 'Patina - A Sign of Wear or a Sign of Value?' 4 December, http://rahnsfurniturerestoration.com/2015/12/04/patina-a-sign-of- 
wear-or-a-sign-of-value/ (accessed 27 June 2018).

Rosenstein, Leon (2009): Antiques: The History of an Idea. Ithaca \& London: Cornell University Press.

Volpe, Erika (2010): 'Tillbaka till 1700-talet' (Back to the 18th century), Kulturvärden 4, 28-35.

von Platen, Joachim \& Göran Tull (eds) (2005): Antikrundan: värdefulla råd och dyrköpta erfarenheter (The Antiques Roadshow: valuable advice and dearly-bought experiences), Stockholm: B. Wahlström.

Walker, Katherine (2012): 'The masterpiece in my attic: The changing role of antiques', Bob Batchelor (ed): Cult Pop Culture: How the Fringe Became Mainstream: Volume 3: Everyday Cult, New York: Praeger, 17-28.

Wind, Eric (2017): Aged to perfection - The patina trend in watches, https://www. christies.com/features/The-patina-trend-in-watches-8023-1.aspx (accessed 27 June 2018). 